\title{
Comparison of heart rate recovery between normotensive young adults with and without a parental history of hypertension
}

\author{
Satyajit Bagudai', Hari Prasad Upadhyay ${ }^{2}$ \\ ${ }^{1}$ Assistant Professor, Department of Physiology, College of Medical Sciences \& Teaching Hospital, Bharatpur, Chitwan, \\ Nepal, ${ }^{2}$ Lecturer, Department of Community Medicine, College of Medical Sciences \& Teaching Hospital, Bharatpur, \\ Chitwan, Nepal
}

Background: Studies have reported that off springs of hypertensive parents are more likely to develop hypertension. Dysfunction of target organ starts even before the diagnosis of hypertension. Cardiac autonomic dysfunction may be the initial event in the pathogenesis of hypertension. Till now very few studies have been done to find the early outcomes in the cardiac autonomic functions in the normotensive siblings of hypertensive patients. Heart rate recovery after exercise is a useful marker for cardiac autonomic function. Since the etiopathogenesis of hypertension is expected to affect the autonomic cardiovascular parameters even before the prehypertensive stage, the following study was carried out to analyze the heart rate recovery, in the descendent non- hypertensive young adults with and without parental history of hypertension. Aims and Objective: This research study was aimed to quantify and compare the difference (if any) of heart rate recovery in response to 3 minute step test between non hypertensive children of non- hypertensive and hypertensive parents within an age group of 18-22 years. Materials and Methods: A total of 63 normotensive students were divided into one hypertensive parents(HP) group containing students with parental history of hypertension) and one non hypertensive parents group(NHP) having students without parental history of hypertension). Each student was subjected to 3minute Master step test. Recordings of heart rate were made before and after exercise. Heart rate recovery index (HRRI) of 1 minute (HRRI1), as well as in 2,3 and 4 minute (HRRI2, HRRI3, HRRI4) were calculated and analyzed. Results: The resting (basal) heart rate as well as $1^{\text {st }}$ minute heart rate recovery index (HRRI1) was not significantly different in the two groups. Likewise, the $2^{\text {nd }}$ minute (HRRI2), $3^{\text {rd }}$ minute (HRRI3), and $4^{\text {th }}$ minute HRRI (HRR4) respectively were also not significantly different between the two groups. Conclusion: This study concluded that there is no significant difference in heart rate recovery among non-hypertensive young adults, with and without parental history of hypertension.

Key words: Autonomic dysfunction; Exercise; Non hypertensive young adults; 3-minute step test; Heart rate recovery index (HRRI)

\section{INTRODUCTION}

Essential hypertension is still continuing as one of the most prevalent cause of morbidity which is not only acting as a risk factor for cardiovascular mortality but also is involved in a considerable health care expenditure globally. This multi organ and multi symptomatic disease develops and progresses slowly spanning several decades of life. Studies have reported that $25 \%$ of children with one hypertensive parent and $50 \%$ of the children with two hypertensive parents will eventually become hypertensive. ${ }^{1,2}$ This indicates the role of heredity playing a vital role in the development of the disease. Evidence from reported works has shown the autonomic dysfunction as a strong basis for the initiation and sustained maintenance of hypertension. ${ }^{3}$ Supportive data are there that even if 
hypertension is more common in middle aged and elderly population, prehypertension is more common in young adults especially in those who have family history of hypertension..$^{4-8}$ Some recent studies have pointed out that an increased sympathetic and decreased parasympathetic activity in young adults alters the sympatho-vagal balance which might be the predisposing mechanism for the initiation of prehypertension. ${ }^{9}{ }^{10}$ In spite of these recent reports, there is a meager data regarding the nature of change in autonomic balance which slowly changes the normotensive to develop into a state of pre-hypertension. Till date not much study has been reported in this part of the world to find out the stated scenario.

Heart rate recovery (HRR) is defined as the rate at which heart rate decreases within the following minutes after exercise. ${ }^{11,12}$ It reflects the dynamic balance and coordinated interplay between parasympathetic reactivation and sympathetic withdrawal. ${ }^{12-14} \mathrm{Abnormal}$ heart rate recovery after exercise is an easy- to- measure tool for assessing reduced parasympathetic activity. ${ }^{15,16}$ Delay in the heart rate recovery after exercise has also been shown in many studies to be an independent predictor for both cardiovascular and all-cause mortality. ${ }^{17,18}$ With the above background, the current study was designed and executed COMS, Bharatpur to compare the HRR in young normotensive students with and without a parental history of hypertension, with an aim to understand whether any relation exist between heredity and imbalance of parasympathetic autonomic activity or not. The output of the research would highlight some authenticate data regarding the cardiovascular autonomic regulation which might be helpful in finding ways for prevention of prehypertension.

\section{MATERIALS AND METHODS}

A comparative study was done in the Department of Physiology of College of Medical Sciences and Teaching Hospital, Bharatpur from October- December 2019. The study group was comprised of a total 64 students of either gender from $1^{\text {st }}, 2^{\text {nd }}$ year MBBS and BDS. The parental history of primary hypertension was obtained from the parents of the students. From parental history data, the participant students were divided into two groups. A non-hypertensive parents group (NHP) was having 41 of the students without a parental history of hypertension while another hypertensive parents group (HP) was having 23 students with a parental history of hypertension (single or both parents suffering from hypertension). The common inclusion criteria for both groups were that the students must be healthy and in the age group of 18-22yrs. They should be nonsmoker and nonalcoholic. Students having any recent or past systemic illness as well as using any type of over the counter or prescription medication or supplements were excluded from the study. The study was done in the Human Physiology laboratory in the department of Physiology of COMS between 9AM-11AM. On the day of the study participants were instructed to report to the Exercise Physiology laboratory after a light breakfast with an abstinence from alcohol, caffeine or any type of strenuous activities for the preceding 24 hours. The participants were explained in detail about the procedure. All subjects gave written consent before the starting of procedure. The temperature of the recording room was maintained between $25-28^{\circ} \mathrm{C}$. The participants were asked to void the urine before the start of the procedure. After 10 minutes of rest, age, weight, heights were taken and resting (basal) heart rate as well as blood pressure was recorded in a sitting posture. With the help of a metronome, 3-minuteMaster two step exercise test were conducted. The participants were instructed to come out of the exercise maneuver in the event of any type of discomfort. Heart rate was recorded just after the exercise as well as 1,2 and 3 and 4 minutes after exercise in a sitting posture. Heart rate recovery index(HRRI) was calculated by subtracting maximum heart rate achieved just after exercise by the heart rate measured in the $1^{\text {st }}, 2^{\text {nd }}, 3^{\text {rd }}$ and $4^{\text {th }}$ minute of post-exercise period. The data were examined and expressed as mean $\pm \mathrm{SD}$. Changes in parameters within the group were analyzed using student's paired t-test for normally distributed data. Comparisons between the variables were analyzed using independent and paired $t$ test. The null hypothesis was rejected at $\mathrm{p}<0.05$. SPSS version 20 and Microsoft excel were used for analysis of data.

\section{RESULTS}

The mean age of the HP group was $19.78 \pm 0.90$ and that of the NHP group was $19.93 \pm 0.93$ years. There was no significant difference in age among both the groups $(\mathrm{p}=0.55)$. There was also no significant difference in terms of BMI $\left(21.54 \pm 4.34\right.$ and $21.28 \pm 4.20 \mathrm{Kg} / \mathrm{m}^{2}$ respectively, $\mathrm{p}=0.81)$, and resting heart rate, $(88.78 \pm 13.94$ and $95.66 \pm 15.17$ respectively, $\mathrm{p}=0.08$ ) (Table 1$)$.

\begin{tabular}{|c|c|c|c|c|}
\hline Variable & $\begin{array}{c}\text { NHP group } \\
(n=41) \\
\text { Mean } \pm S D\end{array}$ & $\begin{array}{c}\text { HP group } \\
(n=23) \\
\text { Mean } \pm S D\end{array}$ & $\begin{array}{c}t \\
\text { value }\end{array}$ & $\begin{array}{c}P \\
\text { value }\end{array}$ \\
\hline Age (Years) & $19.93 \pm 0.93$ & $19.78 \pm 0.90$ & 0.61 & 0.55 \\
\hline BMI $\left(\mathrm{kg} / \mathrm{m}^{2}\right)$ & $21.28 \pm 4.20$ & $21.54 \pm 4.34$ & -0.236 & 0.81 \\
\hline $\begin{array}{l}\text { Resting Heart } \\
\text { rate in beats } \\
\text { per minute }\end{array}$ & $95.66 \pm 15.17$ & $88.78 \pm 13.94$ & 1.790 & 0.08 \\
\hline
\end{tabular}


With a successful completion of the heart rate recordings at different times after 3-minute exercise, no statistically significant difference was observed between the hypertensive parents and non- hypertensive parents group in terms of maximum heart rate achieved (154.09 \pm 18.56 and $157.76 \pm 29$ respectively, $\mathrm{p}=0.462)$. The $1^{\text {st }}$ minute HRRI was not significantly different in the two groups (31.65 \pm 9.28 and $27.51 \pm 10.28$ respectively, $\mathrm{p}=0.115)$. Similarly, the $2^{\text {nd }}$ minute HRRI $(40.78 \pm 10.25$ and $39.32 \pm 14.50$ respectively, $\mathrm{p}=0.67), 3^{\text {rd }}$ minute HRRI $(47.83 \pm 10.43$ and $42.24 \pm 12.43$ respectively, $\mathrm{p}=0.073)$ and $4^{\text {th }}$ minute

\begin{tabular}{llllc}
$\begin{array}{l}\text { Table 2: Distribution of the results of exercise } \\
\text { test among groups }\end{array}$ & & & \\
\hline $\begin{array}{l}\text { Variable } \\
\text { (Heart rate } \\
\text { in beats per } \\
\text { minute) }\end{array}$ & NHP group & HP group & $\begin{array}{c}\boldsymbol{t} \\
\text { value }\end{array}$ & $\begin{array}{c}\boldsymbol{P} \\
\text { value }\end{array}$ \\
\hline $\begin{array}{l}\text { Just after } \\
\text { exercise }\end{array}$ & $157.76 \pm 19.29$ & $154.09 \pm 18.56$ & 0.740 & 0.462 \\
HRRI1 & $27.51 \pm 10.28$ & $31.65 \pm 9.28$ & -1.599 & 0.115 \\
HRRI2 & $39.32 \pm 14.50$ & $40.78 \pm 10.25$ & -0.428 & 0.670 \\
HRRI3 & $42.24 \pm 12.43$ & $47.83 \pm 10.43$ & -1.823 & 0.073 \\
HRRI4 & $46.05 \pm 15.21$ & $49.91 \pm 11.54$ & -1.058 & 0.294 \\
\hline
\end{tabular}

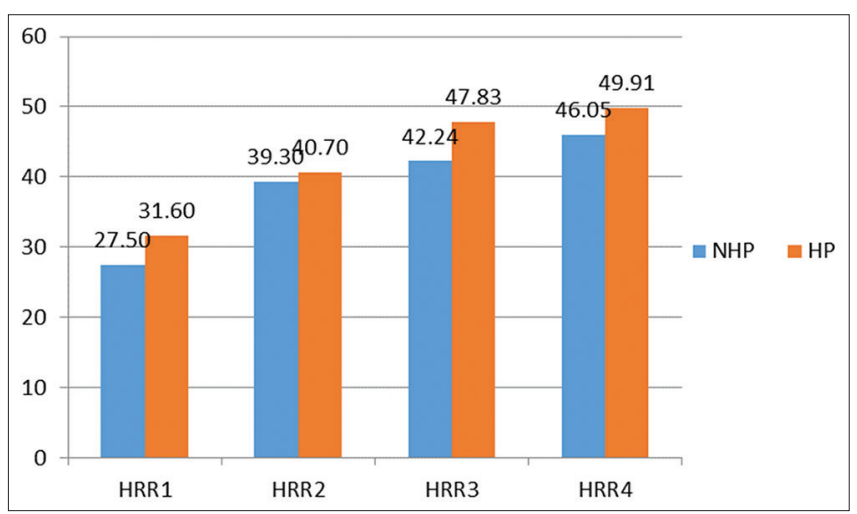

Figure 1: Bar graph showing mean heart rate recovery index in different minutes after exercise of the two groups

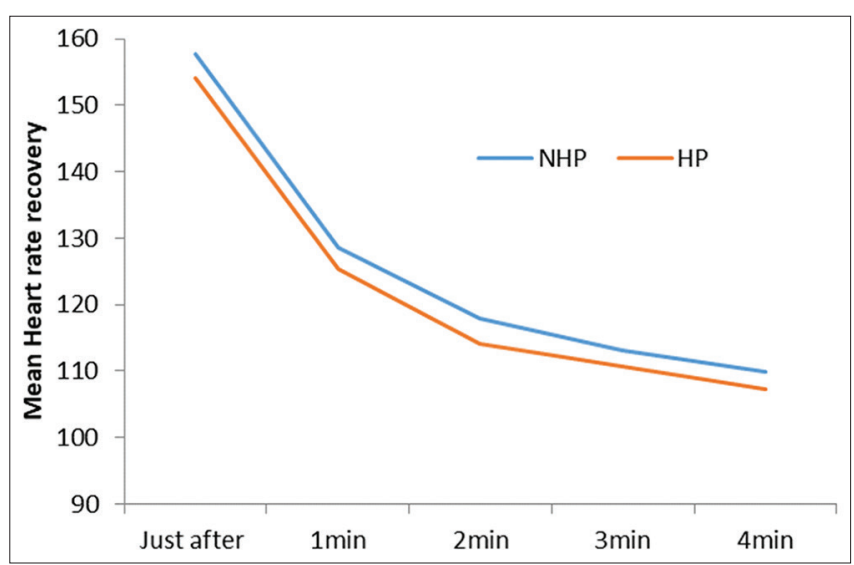

Figure 2: The Mean heart rate recovering in different minutes after exercise of both groups
HRRI (49.91 \pm 11.54 respectively, $\mathrm{p}=0.294)$ were also not significant as depicted in (Table 2, Figure 1 and Figure 2).

\section{DISCUSSION}

In our present study we did not find any significant difference between the resting heart rate in two groups $(p=0.08)$. Even if both types of autonomic nervous system (sympathetic and parasympathetic) are involved in maintaining the resting heart rate but more so it is the predominant vagal parasympathetic tone that determines the resting heart rate in healthy resting individuals. ${ }^{19}$ With no significant difference in the age and BMI between both groups, this finding indicates that at rest, vagal parasympathetic activity between the two groups are insignificant. So at least in resting state, without disease affection, the vagal function is not altered in the study group. The maximum heart rate achieved just after the exercise is also not showing any significant difference between these two group $(p=0.46)$. Maximum heart rate achieved during a physical exercise is a function of parasympathetic withdrawal and sympathetic activation..$^{20}$ So in this parameter also both groups are showing the same type of changes which indicates that the hypertensive parents (HP) group has no difference in parasympathetic withdrawal and sympathetic activation from the nonhypertensive parents (NHP) group. In all type of heart arte recovery index the $\mathrm{p}$ value was more than 0.05 . It points to the fact that the recovery of heart rate after an exercise stress test is following the same pattern irrespective of the history of hereditary. In normal healthy individuals, a fast decrease in heart rate is observed in the first 30 seconds after exercise followed by a relatively slower decrease. Activation of parasympathetic nervous system is predominant in the decrease of heart rate observed in the early period after exercise whereas the withdrawal of sympathetic system is more effective in the later period. ${ }^{19}$ In both these autonomic parameters, the hypertensive parents (HP) group is not showing any difference from control group. All these findings are supporting the results of an another same type of work done by Jha et al in $2018 .{ }^{21}$ Contradictory findings have been reported from the work of Krishnan et al, Chinagudi et al and Pal et al which has shown an increased sympathetic and a decreased parasympathetic activity in the non- hypertensive healthy off- springs of hypertensive parents. ${ }^{10,22,23}$ Similar type of study done by Stolarz K has reported that the sympathetic activity was increased in the normotensive young healthy adults with a genetic history of hypertension without a change in their parasympathetic function ${ }^{24}$. Whereas all the above mentioned works had heart rate variability as their tool of assessment, the works of Jha et al have taken heart rate recovery as their tool of autonomic assessment. Yamada et al and Noll et al have 
measured muscle sympathetic activity using micrography in normotensive young offspring of parents with and without hypertension..$^{25,26}$ Both studies have failed to observe any significant difference in the baseline sympathetic nerve activity between two participating groups. Similarly, Calhoun et al have reported that sympathetic reactivity to cold pressor test was not related to the parental history of hypertension in subjects of white ethnicity. ${ }^{27}$

These different conflicting findings even with the works done by taking the same tool of assessment, is still posing an inconclusive consensus regarding the association between early cardiac autonomic dysfunction with genetics. Large scale prospective studies have shown an association of both maternal and paternal blood pressure with the blood pressure of their offspring. ${ }^{28}$ Similarly other works have shown in their case control, cohort and longitudinal studies that parental hypertension to be strongly associated with hypertension risk. ${ }^{28,29,5} \mathrm{~A}$ constant advance in our understanding of blood pressure have underscored its complex pathophysiology, in which genetic and environmental factors combine for a vast number of physiological pathways and mechanisms ultimately leading to the phenotype. Till now, with many epidemiological studies giving a satisfactory understanding of the environmental factors relating to blood pressure, specifically with regard to diet and exercise, the exact contributory role of genetics has been challenging. The completion of Human Genome Project and HapMap initiatives has found a multitude of genome-wide association studies that have given the impetus to discover these genetic variants. Recent works have reported 280 genetic variants to be associated with a risk of hypertension, along with coronary artery disease for which hypertension is thought to be have a causal pathway. ${ }^{30-33}$ In a recent report by Warren et al a multiple of single nucleotide polymorphism (SNP) in a risk score accounted for a difference in systolic blood pressure values up to10 $\mathrm{mmHg}$ between individual. ${ }^{34}$ Despite this, the combined contribution of these multiple genetic variant to heritability estimates remains lower than expected. ${ }^{35,36}$ This has led to questions about the missing heritability. ${ }^{37}$ These facts have also supported in other complex diseases like coronary disease ${ }^{37}$ Even if we expect that many more as yet undiscovered loci will help to explain about the missing heritability, now from all the works done so far, we conclude that at least in part, these contradictory reports could also be related to an overestimation of initial hereditary estimates as well as of the phenotypic pleiotropy.

\section{CONCLUSION}

There is no difference in the heart rate recovery index in $1^{\text {st }}$ to $4^{\text {th }}$ minute in the healthy young normotensive adults with and without a family history of hypertension. These findings suggest that without the association of pre-hypertension and hypertension as well as other associated comorbidities, a family history of hypertension as such is not associated with a dysfunction of autonomic nervous system.

\section{Limitations of the study}

The major limitation of our present study is the less sample size of the study group. Inclusion of other confounding factors which predispose hypertension like diet, sodium intake, physical activity, age of onset of parental hypertension would have provided a better conclusion for the study. Other autonomic assessments as well as more accurate methods of sympathetic activity like measurement of plasma and urinary catecholamine metabolites should also have been compared. Therefore, more future studies with a consideration of the above facts can be done to make us reach a final conclusion regarding the association of genetics with the cardiac autonomic dysfunction even before the development of prehypertension.

\section{Conflict of interests}

The authors declare that there is no conflict of interests.

\section{REFERENCES}

1. Schneider GM, Jacobs DW, Gevirtz RN and O'Connor DT. Cardiovascular hemodynamic response to repeated mental stress in normotensive subjects at genetic risk of hypertension: evidence of enhanced reactivity, blunted adaptation, and delayed recovery. Journal of human hypertension 2003; 17: 829-840.

https://doi.org/10.1038/sj.jhh.1001624

2. Morshedi-Meibodi A, Larson MG, Levy D, O’Donnell CJ and Vasan RS. Heart rate recovery after treadmill exercise testing and risk of cardiovascular disease events (The Framingham Heart Study). Ame J Cardiol 2002; 90(8):848-852.

3. Julius $\mathrm{S}$. Autonomic nervous system dysregulation in human hypertension. Am J Cardiol 1991; 67; B3-B7.

4. Ortega FHN, Herrera JC, Baute LH, Garc'ıa AC, Gallestey JB and Ramos MR. Genetic and environmental factors in essential arterial hypertension in an urban population of Cuba. Archivos del Instituto de Cardiolog'ı de M'exico 1995; 65(5)426-434.

5. Wang NY, Young JH, Meoni LA, Ford DE, Erlinger TP and Klag MJ. Blood pressure change and risk of hypertension associated with parental hypertension: The Johns Hopkins precursors study. Archives of Internal Medicine 2008;168(6): 643-648.

https://doi.org/10.1001/archinte.168.6.643

6. Lopes HF, Silva HB and Consolim-Colombo FM. Autonomical abnormalities demonstrable in young normotensive subjects who are children of hypertensive parents. Brazilian Journal of Medical and Biological Research 2000; 33(1):51-54. https://doi.org/10.1590/S0100-879X2000000100007

7. deVisser DC, VanHooft IMS, VanDoornen JP, Hofman A, Orlebeke JF and Grobbee DE. Cardiovascular response to physical stress in offspring of hypertensive parents: Dutch hypertension and offspring study. Journal of Human Hypertension 1996;10(12):781-788. 
8. Sowmya R, Maruthy $\mathrm{KN}$, and Gupta R. Cardiovascular autonomic responses to whole body isotonic exercise in normotensive healthy young adult males with parental history of hypertension. Indian Journal of Physiology and Pharmacology 2010; 54(1):37-44.

9. Pal GK, Amudharaj D and Pal P. Study of sympatho-vagal imbalance by spectral analysis of heart rate variability in young pre-hypertensives. Indian Journal of Physiology and Pharmacology 2011;55(4) 61-67.

10. Muralikrishnan K, Balasubramanian K and Rao BV. Heart Rate Variability In Normotensive Subjects With Family History of Hypertension. Indian J Physiol Pharmacol 2011;55(3):253-261.

11. Cole CR, Blackstone EH, Pashkow FJ, Snader CE and Lauer MS. Heart-rate recovery immediately after exercise as a predictor of mortality. N Engl J Med 1999; 341:1351-1357. https://doi.org/10.1056/NEJM199910283411804

12. Pecanha T, Silva-Junior ND and Forjaz CL. Heart rate recovery: autonomic determinants, methods of assessment and association with mortality and cardiovascular diseases. Clin Physiol Funct Imaging 2014;34:327-339.

https://doi.org/10.1111/cpf.12102

13. Coote JH. Recovery of heart rate following intense dynamic exercise. Exp Physiol 2010; 95:431-440.

https://doi.org/10.1113/expphysiol.2009.047548

14. Borresen $\mathrm{J}$ and Lambert MI. Autonomic control of heart rate during and after exercise: measurements and implications for monitoring training status. Sports Med 2008; 38:633-646. https://doi.org/10.2165/00007256-200838080-00002

15. Imai $\mathrm{K}$, Sato $\mathrm{H}$, Hori $\mathrm{M}$, Kusuoka $\mathrm{H}$, Ozaki $\mathrm{H}$, Yokoyama $\mathrm{H}$, et al. Vagally mediated heart rate recovery after exercise is accelerated in athletes but blunted in patients with chronic heart failure. J Am Coll Cardiol 1994;24:1529-1535.

16. Arai Y, Saul JP, Albrecht P, Hartley LH, Lilly LS, Cohen RJ, et al. Modulation of cardiac autonomic activity during and immediately after exercise. Am J Physiol 1989;256(1)H132-141. https://doi.org/10.1152/ajpheart.1989.256.1.H132

17. Ho JS, Fitzergard SJ, Barlow CE, Cannaday JJ, Kohl HW, Haskel WL, et al. Risk of mortality increases with increasing number of abnormal ST parameters recorded during exercise testing. Eur J Cardiovasc Prev Rehabil 2010;17:462-468. https://doi.org/10.1097/HJR.0b013e328336a10d

18. Savonen KP, Kiviniemi V, Laaksonen DE, Lakka TA, Laukkanen JA, Tuomainen TP, et al. Two minute heart rate recovery after cycle ergometer exercise and all cause mortality in middle aged men. J Intern Med 2011;270:589-596.

https://doi.org/10.1111/j.1365-2796.2011.02434.x

19. Koeppen BM and Stanton BA. Integrated control of cardiovascular system. Bern and Levy Physiology, 6e (Updated edition). Mosby(Elsevier). Missouri 2012:393-414.

20. Poehling PC and Llewellyn TL. The effects of submaximal and maximal exercise on heart arte variability. Int J Exerc Sci 2019;12(2):9-14.

21. Jha A, Karki P, Agrahari R and Kumari N. Effect of exercise on heart arte recovery index in normotensive offspring with family history of hypertension. Int J Res Med Sci 2018;6(4):1101-1103. https://doi.org/10.18203/2320-6012.jirms20181263

22. Chinagudi S, Herur A, Patil S, Sasikala GV and Roopa A. Comparative study of Heart rate variability in normotensive offsprings of hypertensive parents. Biomedical Research 24(1): 123-126.

23. Pal GK, Pal P, Nanda N, Lalita V, Datta TK and Adithan C. Sympathovagal Imbalance in Prehypertensive Offspring's of Two Parents versus One Parent Hypertensive. International
Journal of Hypertension 2011.

https://doi.org/10.4061/2011/263170

24. Stolarz K, Grodzicki T, Lubaszewski W, Adamkiewicz-Piejko A, Olszanecka A and Kawecka-Jaszcz K. Heart rate variability in offspring of hypertensive parents. Przegl Lek 2002; 59:892-894.

25. Yamada $\mathrm{Y}$, Miyajima E, Tochikubo $\mathrm{O}$, Matsukawa $\mathrm{T}$, Shionoiri $\mathrm{H}$, Ishii M, et al. Impaired baroreflex changes in muscle sympathetic nerve activity in adolescents who have a family history of essential hypertension. J hypertension. Supplement: official J Inter Soci Hypertension 1988;6(4):S525-S528.

https://doi.org/10.1097/00004872-198812040-00165

26. Noll G, Wenzel RR, Sheinder M, Oesch V, Binggelic C, Shaw S, et al. Increased activation of sympathetic nervous system and endothelin by mental stress in normotensive offspring of hypertensive parents. Circulation 1996;93(5):886-889.

https://doi.org/10.1161/01.CIR.93.5.866

27. Calhoun DA and Mutinga ML. Race, family history of hypertension, and sympathetic response to cold pressor testing. Blood pressure 1997;6(4):209-213. https://doi.org/10.3109/08037059709062071

28. Havlik RJ, Garrison RJ, Feinleib M, Kannel WB, Castelli WP and McNamara PM. Blood pressure aggregation in families. Am J Epidemiol 1979;110(3):304-312. https://doi.org/10.1093/oxfordjournals.aje.a112815

29. Higgins MW, Keller JB, Metzner HL, Moore FE and Ostrander LD. Studies of blood pressure in Tecumseh, Michigan, II: antecedents in childhood of high blood pressure in young adults. Hypertension 1980;2(4):117-123. https://doi.org/10.1161/01.HYP.2.4.117

30. Friedman GD, Selby JV, Quesenberry CP, Armstrong MA and Klatsky AL. Precursors of essential hypertension: body weight, alcohol and salt use, and parental history of hypertension. Prev Med 1988;17(4):387-402.

31. Thomas CB and Duszynski KR. Blood pressure levels in young adulthood as predictors of hypertension and the fate of the cold pressor test. Johns Hopkins Med J 1982;151(3):93-100.

32. Wellcome Trust Case Control Consotium. Genome-wide association study of 14,000 cases of seven common diseases and 3,000 shared controls. Nature 2007; 447:661-678. https://doi.org/10.1038/nature05911

33. Ehret GB, Chasman DI, Jackson AU, Schmidt EM, Johnson T, Thorleifsson $\mathrm{G}$, et al. The genetics of blood pressure regulation and its target organs from association studies in 342,415 individuals. Nat Genet 2016; 48:1171-1184. https://doi.org/10.1038/ng.3667

34. Warren HR, Evangelou E, Cabrera CP, Gao H, Ren M, Mifsud B, et al. Genome-wide association analysis identifies novel blood pressure loci and offers biological insights into cardiovascular risk. Nat Genet 2017; 49:403-415. https://doi.org/10.1038/ng.3768

35. Hoffmann TJ, Ehret GB, Nandakumar P, Ranatunga D, Schaefer C, Kwok PY, et al. Genome-wide association analyses using electronic health records identify new loci influencing blood pressure variation. Nat Genet 2017; 49:54-64. https://doi.org/10.1038/ng.3715

36. Patel RS, Masi S and Taddi S. Understanding the role of genetics in hypertension. European Heart Journal 2017; 38:2309-2312. https://doi.org/10.1093/eurheartj/ehx273

37. Manolio TA, Collins FS, Cox NJ, Goldstein DB, Hindorff LA, Hunter DJ, et al. Finding the missing heritability of complex diseases. Nature;2009; 461:747-753. https://doi.org/10.1038/nature08494 
Authors Contribution:

SB- Concept and design of the study, collected data and review of literature, manuscript preparation, critical revision of the manuscript and preparing first draft of manuscript; HPU- statistically analyzed and interpreted, review of study.

Work attributed to:

Department of Physiology, College of Medical Sciences \& Teaching Hospital, Bharatpur, Chitwan, Nepal.

Orcid ID:

Dr. Satyajit Bagudai - (B) http://orcid.org/0000-0002-6165-9314

Source of Support: None, Conflict of Interest: None. 